\title{
Levator Palpebrae Superioris
}

National Cancer Institute

\section{Source}

National Cancer Institute. Levator Palpebrae Superioris. NCI Thesaurus. Code C52802.

A thin, flat, triangular muscle originating from the lesser wing of the sphenoid above and in front of the optic canal and inserts at the upper marg in of the superior tarsal plate to elevate the upper eye lid. 